\title{
A experiência brasileira em orçamento-programa - uma primeira visão
}

José Teixeira Machado Jr. (in memoriam)

Professor da Ebap; Ibam

A concepção de "orçamento-programa" já estava presente à "Comissão de Estudos Financeiros e Econômicos dos Estados e Municípios" convocada pelo Decreto no 20.631, de 9 de novembro de 1931, com o objetivo de "proceder ao estudo minucioso da situação econômico-financeira de cada Estado e seus Municípios, facultando ao Governo Provisório, com os subsídios que lhe oferecer, a decretação de medidas necessárias à reorganização econômica e administrativa do país". ${ }^{1}$

De fato, o Decreto-Lei no 1.804, de 24 de novembro de 1939, e, posteriormente, o Decreto-Lei no 2.416, de 17 de julho de 1940, inovaram grandemente na classificação das transações governamentais, criando um sistema dentro do caos até então vigente.

Assim é que a receita dos estados e municípios recebeu uma classificação em que se procurava ressaltar três critérios: 1) a "natureza", compreendendo as receitas tributárias, patrimoniais, industriais etc.; 2) em seguida, a natureza era desdobrada em "espécie" (imposto de vendas e consignações, taxa de coleta de lixo, renda imobiliária etc.); 3) o terceiro desdobramento dizia respeito à "incidência" (sobre a propriedade, sobre a circulação da riqueza etc.). A essa classificação se atribuía um código numérico, assaz engenhoso mas não decimal, procurando identificar a natureza, a espécie e a incidência da receita.

Quanto à despesa, o sistema de classificação do Decreto-Lei no 2.416/40 seguia também um desdobramento tríplice em 1) "serviços" (administração geral, educação pública etc.); 2) "subserviços" (governo, ensino superior etc.) e 3) "elementos", compreendendo os meios de que a administração se utiliza para alcançar seus objetivos: pessoal, material, despesas diversas. "Os 'serviços' têm aqui o sentido de fins, ou destinos atribuídos à despesa, enquanto os 'elementos' representam os meios empregados ou os instrumentos da despesa."

Como se verifica, o sistema classificatório da despesa era simples, prático e racional. O Decreto-Lei adotou, em um dos seus anexos, uma relação de 10 serviços (ou funções, na

\footnotetext{
${ }^{1}$ ALMIRO, Affonso. Técnica orçamentária — estados e municípios. 1. ed. Rio de Janeiro: Editora Guaíra Limitada. p. 17.

${ }^{2}$ Almiro, op. cit., p. 36. Grifos do original.
} 
terminologia moderna), cada qual subdividido em 10 subserviços, ou subfunções, como nos mostra o exemplo do serviço 4 - Saúde Pública, que se desdobrava em:

4.0 - administração superior

4.1 - assistência hospitalar

4.2 - ambulatórios

4.3 - assistência pública

4.4 - assistência domiciliar

4.5 - vago

4.6 - serviços de inspeção

4.7 - serviços técnicos especializados

4.8 - subvenções, contribuições e auxílios

4.9 - serviços diversos.

Não é esta, evidentemente, a oportunidade para se discutir a precisão das funções e subfunções criadas pelo Decreto-Lei no 2.416/40. Cumpre assinalar apenas que nele estava a base para a classificação funcional das contas públicas, representativas estas das transações governamentais. Não se criou, porém, um nome para o novo tipo de classificação que se pretendia introduzir, como viria, anos após, fazer a "Comissão Hoover" do governo norteamericano, batizando o resultado de seu trabalho com o nome de performance budgeting, geralmente traduzido por "orçamento-programa".

Todavia, não resultou, tão somente, da falta de um nome o não desenvolvimento da prática do orçamento-programa no Brasil.

Faltava, por exemplo, à época, uma teoria que elevasse o orçamento a uma categoria independente da contabilidade. O primeiro nada mais era que um instrumento de operação da segunda, dentro de um contexto que desconhecia a administração como um processo operacional. Como o orçamento e a contabilidade utilizam a conta como instrumento de registro, de análise e de representação e como a contabilidade é a ciência que estuda e desenvolve a teoria das contas, achou-se apropriado que o orçamento fosse concebido e operado como um de seus instrumentos técnicos.

Não se tinham, pelo menos no Brasil, difundido, ainda, os conceitos basilares da teoria da administração, na qual o orçamento passa a ocupar posição destacada como um dos instrumentos de formulação dos quadros de programas a realizar no exercício futuro, depois de escolhido um rumo entre as várias alternativas que se podem apresentar ao administrador, equacionando para este os recursos necessários à condução dos negócios públicos ou das empresas privadas, tanto faz, em um período de tempo prefixado.

Não podemos, também, esquecer que os próprios estudos econômicos pairavam em um plano eminentemente teórico e os idealizadores das normas aprovadas pelo Decreto-Lei no 2.416/40 não visualizaram a necessidade prática de ser o orçamento estruturado nas três categorias fundamentais da classificação econômica: despesas de custeio, de transferência 
e de capital. Ou, talvez, acharam que os funcionários estaduais e municipais seriam, ao tempo, incapazes de manipular um orçamento em que se pusessem em evidência aquelas três categorias.

A concepção do orçamento como a "lei que estima a receita e fixa a despesa de um Governo para um determinado período de tempo" não levava, como não leva ainda hoje, a qualquer entendimento de que o orçamento é um plano de trabalho. Reduz-se a transmitir o pensamento de que o orçamento deve ser elaborado para facultar às Câmaras Legislativas um efetivo controle sobre os Executivos e, para tanto, bastaria que o orçamento fosse discriminado pelos meios necessários para condução da coisa pública.

Não nos esqueçamos, nesse contexto político-jurídico, de que se entendia o governo como mero expectador do processo econômico e social, sem poderes para uma intervenção efetiva, a não ser em benefício da chamada paz social, e o melhor plano de governo era aquele que menos gastasse. A lição de Gladstone que concebia a despesa pública como um processo de planejamento da ação governamental estava, virtualmente, esquecida.

Faltava, consequentemente, nos idos da década de 1940, a infraestrutura teórica indispensável para o florescimento promissor do orçamento-programa. Por isso mesmo os administradores do Decreto-Lei no 2.416/40 não deram ênfase suficiente à noção de "serviço" como uma função, ou um programa de trabalho, embora a definição acima transcrita de um dos autores das normas aprovadas por aquele diploma legal fosse essencialmente funcional.

As "instruções para a codificação dos orçamentos, expedidos pela Secretaria do Conselho Técnico de Economia e Finanças em 1939", e publicados em fascículo com o Decreto-Lei no 2.416 em 1940, apresentavam, apesar de tudo isso, a despesa classificada, em primeiro plano, pelos serviços, como se pode verificar do seguinte exemplo extraído daquelas instruções:

\begin{tabular}{|c|c|l|}
\hline \multicolumn{2}{|c|}{ Código } & \multirow{2}{*}{ Designação da Despesa } \\
\cline { 1 - 2 } Local & Geral & \\
\hline $8-1$ & Exação e Fiscalização Financeira ("Serviço") \\
\hline $8-1-1$ & Coletoria X \\
\hline $8-1-1-0$ & Pessoal Fixo \\
\hline $8-1-1-1$ & Pessoal Variável \\
\hline $8-1-1-2$ & Material Permanente \\
\hline $8-1-1-3$ & Material de Consumo \\
\hline $8-1-1-4$ & Despesas Diversas ${ }^{3}$ \\
\hline
\end{tabular}

Fonte: Machado Jr. (1967)

No entanto, as referidas instruções deixaram de conceituar o entendimento de "serviços”, preocupando-se, exclusivamente, em fixar a codificação numérica que, para os mesmos,

\footnotetext{
${ }^{3}$ Almiro, op. cit., p. 179.
} 
deveria ser obrigatoriamente utilizada e, dessa forma, não foi possível desenvolver-se a classificação por "serviços" como uma classificação funcional.

Fácil é, pois, identificar a inexistência de uma teoria e de uma mentalidade voltadas para a programação como causa eficiente de, nesse período, não ter surgido uma prática de orçamento-programa, nos estados e municípios brasileiros.

O governo da União, por seu lado, não deu, durante esse mesmo período, nenhum passo no sentido de introduzir o orçamento-programa no serviço público federal, não obstante as melhorias, sucessivas, que se foram obtendo na classificação das contas públicas, especialmente a partir de 1954, mas visando, de modo particular, a apresentação das transações governamentais sob as categorias econômicas.

É curioso observar, por exemplo, que a Cepa (Comissão de Estudos e Projetos Administrativos) não apresentou qualquer recomendação no sentido de introdução do orçamentoprograma na administração pública brasileira, embora na época em que seus relatórios foram concluídos a teoria do orçamento-programa já fosse fartamente difundida em todas as nações e muitos dos técnicos que participaram dos estudos da Cepa fossem profundos conhecedores do assunto ou, no mínimo, informados da existência dessa técnica com farta aplicação nos governos locais, estaduais e federal dos Estados Unidos, antes mesmo das recomendações das Comissões Hoover.

Como vimos no início deste trabalho, o orçamento sempre foi e, em muitos órgãos da administração pública brasileira, ainda o é, entendido e utilizado como um instrumento da contabilidade. Todavia, enquanto no orçamento se fazia, pelo menos nos estados e municípios, uma classificação por "serviços", as apurações contábeis desprezaram inteiramente tal critério classificatório, o que dificultou, ainda mais, o desenvolvimento de um conceito e de uma prática de orçamento-programa.

A partir do segundo semestre de 1957, quando assumimos a cátedra de "Orçamento e Administração Financeira" na Escola Brasileira de Administração Pública, e, em âmbito mais amplo, a partir de 1960, quando se iniciou nossa colaboração efetiva ao Instituto Brasileiro de Administração Municipal com o primeiro curso de orçamento ministrado para funcionários públicos estaduais e municipais de São Paulo, passamos a propugnar pela melhoria dos métodos e sistemas orçamentários, procurando mostrar as vantagens de um orçamento em que as metas a atingir sejam colocadas em primeiro plano, na tentativa de criar no seio daquele funcionalismo uma mentalidade nova de planejamento. Procurávamos, outro tanto, mostrar que as técnicas do orçamento-programa não pertencem a um reino de conhecimentos impenetráveis e que a legislação então vigente não se opunha, ao contrário, favorecia, o desenvolvimento das práticas da programação no orçamento público. Nosso pensamento era, como aliás o é ainda hoje, que a modificação das práticas orçamentárias em qualquer nível de governo só se pode operar por etapas.

É bem verdade que muitas vezes éramos obrigados, em nossas aulas, a dar certa ênfase à classificação por categorias econômicas, porque o projeto em curso no Congresso Nacional e do qual resultaria a Lei no 4.320, de 17 de março de 1964, enfocava, em primeiro plano, esse tipo de classificação, e os participantes dos cursos estavam, muito naturalmente, desejosos de informações sobre tais inovações. 
A Lei no 4.320/64, em seus artigos 11 e 12, fixou as categorias econômicas como regra fundamental para a classificação das transações governamentais em todos os níveis, e deixou a classificação funcional, mais uma vez, como um sistema auxiliar, subsidiário.

Logo no artigo 8o, parágrafo primeiro, ao estabelecer a codificação numérica, reserva para a classificação econômica o código decimal que é complementado pelos 'algarismos caracterizadores da classificação funcional da despesa...". Esta não é objeto do corpo da Lei, aparecendo somente no anexo $\mathrm{n}$ - 5, onde se encontra repetida a técnica do Decreto-Lei $\mathrm{n}^{\circ} \mathrm{o}$ 2.416/40, i.e., a distribuição das funções governamentais em 10 grupos, cada qual subdividido em 10 outros subgrupos.

É bem verdade que a Lei no 4.320/64 refere-se a programas em inúmeros de seus dispositivos, tais como no parágrafo único do artigo 20, o número IV do artigo 22, os artigos 23, 27 e 48, em sua alínea $a$ e, por fim, o artigo 49. No título reservado ao controle orçamentário, a Lei no 4.320 determina, no número III do artigo 75, que o cumprimento do programa de trabalho seja controlado "em termos monetários e em termos de realização de obras e prestação de serviços", e, mais adiante, ao tratar do controle interno, a cargo do Poder Executivo, impõe que "esse controle far-se-á, quando for o caso, em termos de unidades de medida, previamente estabelecidas para cada atividade".

Nada disso, porém, autoriza asseverar-se que a Lei no 4.320 estabeleceu as bases para a implantação do orçamento-programa nas três esferas do governo no Brasil. Não obstante, por um conjunto de circunstâncias que ninguém explica e que ninguém, em consequência, entende, a Lei no 4.320 passou a ser denominada a lei do orçamento-programa, a menos que a classificação econômica das transações governamentais esteja sendo confundida como classificação funcional ou por programas. Urge, pois, que se definam com precisão os conceitos para que a prática não fique à mercê de interpretações apressadas.

Não existe, porém, qualquer impedimento contra a introdução do orçamento-programa em qualquer nível de governo, autarquia, empresa pública ou outro órgão de descentralização administrativa. Isto, evidentemente, não seria feito ao arrepio da Lei, pois, se esta não é taxativa, deixa, como vimos, contudo, em vários de seus dispositivos, imensa margem para interpretação favorável ao orçamento-programa, chegando, mesmo, ao ponto de referir-se a controle em termos de unidade de medida, o que, necessariamente, pressupõe a elaboração de igual sistema de mensuração de atividades ou projetos, o que, de fato, além da classificação apropriada, identifica um orçamento-programa.

Ainda não terminara a votação do projeto que resultaria na Lei no 4.320, quando o governador da Guanabara apresentou ao Legislativo uma proposta orçamentária a que titulou de "orçamento-programa".

Até então, só o governo do Estado do Rio Grande do Sul fizera tentativa séria de introduzir na administração pública brasileira um orçamento-programa. Nenhum outro estado ou município, ou o governo federal que saibamos, tomara a iniciativa de preparar um orçamentoprograma antes do advento da Lei no 4.320 .

Entretanto, mesmo na vigência do Decreto-Lei no 2.416 , muitas tentativas de melhoria das práticas orçamentárias foram realizadas em alguns estados e municípios. Vale acentuar, 
em primeiro plano, o trabalho da Prefeitura Municipal de Belo Horizonte, onde, na verdade, se fez uma tentativa de criar unidades de trabalho para mensuração das atividades administrativas através da pesquisa estatística. Tivemos oportunidade de visitar a seção encarregada desse levantamento, mas, com o afastamento do introdutor da ideia, o trabalho já se encontrava em franca decadência e, em seguida, foi descontinuado. Por esse tempo, Belo Horizonte apresentava um orçamento muito bem elaborado, com um entrosamento feliz entre a classificação do 2.416 e a por categorias econômicas. Não tivemos mais informações sobre o desenvolvimento do sistema orçamentário daquela capital.

A Paraíba, em 1958, tentou um orçamento com base na classificação econômica, seguindo os cânones do que vinha fazendo o Dasp, porém os ilustríssimos deputados estaduais recusaram a proposta por falta de amparo constitucional.

O município de Garça, SP, em 1961, apresentou um orçamento muito bem elaborado à base da classificação que seria, posteriormente, adotada pela Lei no 4.320.

O Plano de Ação do Governo Carvalho Pinto, no estado de São Paulo, não chegou a ser um orçamento-programa. A programação refletiu-se apenas no orçamento de capital, deixando o de custeio inteiramente dentro das normas convencionais e mesmo rotineiras. Por outro lado, não se fez ali qualquer entrosamento entre a programação do orçamento de capital e o de custeio. Decorreu dessa falta de ligação entre os dois orçamentos uma grande defasagem entre a programação econômico-social e seu reflexo no orçamento de custeio que não estava preparado para receber o impacto do aumento das atividades por decorrência de criação de novas condições face ao grande volume de investimento em obras públicas, construção de escolas, construção de casas de agricultura etc. Parece-nos, pois, sob esse ângulo, não foi das melhores a lição deixada em São Paulo em matéria orçamentária.

Dentro dos cânones do orçamento convencional, embora muito melhorado por uma pesquisa constante e um trabalho incessante em busca de novos métodos de elaboração, de controle de execução e de prestação de contas, parece-nos das mais promissoras a experiência que se vem realizando no orçamento do governo do estado do Paraná, de alguns anos a esta parte.

Estritamente dentro dos preceitos da 4.320, mas com o aspecto formal digno de nota, a Prefeitura Municipal de Aracaju vem preparando seus orçamentos e seus balanços, aliando, porém, a ambos, um plano de trabalho, com a demonstração dos projetos e das realizações, respectivamente.

A Prefeitura do Distrito Federal, Brasília, para onde o prof. Lordello de Mello recrutou uma plêiade de moços recém-egressos da Escola Brasileira de Administração Pública, altamente motivados e desejosos de projetar-se no cenário técnico-administrativo do país, vem elaborando e aperfeiçoando, ano a ano, um documento a que denomina de orçamento-programa.

A Previdência Social, que constitui um campo ótimo para o desenvolvimento da ideia do orçamento-programa, tem, no entanto, se mostrado indiferente, apática mesmo ao aperfeiçoamento do sistema convencional, na maioria dos Institutos. O "Plano de Ação da Previdência Social", recém-promulgado pelo sr. ministro do Trabalho e Previdência Social, incluiu, como 
um dos seus itens, a introdução do orçamento-programa nas instituições previdenciárias. No entanto, a estrutura organizativa dos IAPs atribuída pela Lei Orgânica da Previdência Social e seu Regulamento não auxiliam o desenvolvimento da ideia do orçamento-programa, porque estruturam as Divisões de Orçamento dentro das Contadorias Gerais, seguindo o velho preceito já comentado neste artigo, o que, pela deformação profissional, impede que brote e se desenvolva qualquer ideia que não seja estritamente contábil.

É, portanto, imperioso que o "Paps" siga o exemplo do Ipase e eleve o órgão de orçamento a um plano independente, aliado ao planejamento, junto ao Gabinete do diretor-geral do DNPS e da Direção de cada Instituto.

Tivemos oportunidade de colaborar, com o saudoso colega Ismar Dias da Silva, na estruturação do órgão de orçamento do Ipase, onde uma pesquisa muito honesta foi realizada visando a criação de uma Divisão com autoridade real para planejar e orçamentar as operações daquele Instituto, que, entretanto, também ainda não evoluiu para o orçamento-programa como instrumento efetivo de trabalho.

Relacionamos, assim, ao correr da memória, algumas das experiências que, de uma forma ou de outra, têm contribuído para o aperfeiçoamento da metodologia orçamentária no Brasil, mesmo que se tratasse, apenas, de um esforço para melhorar as práticas convencionais do orçamento público.

Não podemos, no entanto, esquecer o esforço que a Sudene vem fazendo, no Nordeste, para introduzir, em nível estadual e municipal, o orçamento-programa, ora ministrando cursos especiais sobre o assunto, ora prestando assistência técnica diretamente aos governos interessados. Esta ação positiva e contínua da Sudene tem, no mínimo, contribuído para a modificação da mentalidade dos funcionários estaduais e municipais, encarregados dos respectivos orçamentos, como pudemos observar, pessoalmente, em recente experiência na Paraíba.

Todavia, como o escopo deste trabalho é examinar a experiência brasileira em orçamento-programa, deter-nos-emos, de agora em diante, a tecer comentários sobre trabalhos que, por seus próprios autores, têm sido denominados de orçamento-programa, mas apresentam, efetivamente, de um modo ou de outro, características que justificam, até certo ponto, esse batismo. Nessa ordem de ideias, analisaremos as experiências do Rio Grande do Sul, da Guanabara, de Brasília e do Governo Federal.

\section{Rio Grande do Sul}

A solução que fora experimentada nesse estado seguia, muito de perto, o esquema geral aconselhado pela Cepal. Adotava uma divisão primária em despesas de custeio e despesas de capital, com indicação do órgão executor. Conjugava, por consequência, as duas classificações: por categorias econômicas e funcional.

A classificação funcional desdobrava-se nos seguintes níveis: Função, Programa, Subprograma e Atividade, para as despesas de custeio, e Função, Programa e Projeto, para as despesas de capital. 
Convém assinalar, porém, que dada atividade pode comportar despesas de capital, embora, na verdade, a maioria das despesas de uma atividade seja de natureza corrente, especialmente de custeio. A substituição dos móveis de uma sala de aula, p. ex., classifica-se, necessariamente, como despesa de capital, mas não constitui um projeto porque não é atividade nova nem amplia a já existente. Achamos, por isso, que as duas classificações devem marchar paralelas, sem se confundirem, apresentando-se, apenas, resumo explicativo das categorias econômicas distribuídas pelas categorias funcionais e, se for julgado conveniente, um resumo das categorias funcionais distribuídas pelas econômicas.

O sistema gaúcho não apresentou qualquer tentativa de mensuração do trabalho, ficando, portanto, na classificação das operações governamentais. E, na verdade, a experiência, após 31 de março de 1964, infortunadamente, foi descontinuada.

Vejamos um exemplo do esquema do Rio Grande do Sul.

\section{Secretaria de Obras Públicas \\ Orçamento de Custeio}

\begin{tabular}{|lll|}
\hline Função & Programa & Órgão executor \\
\hline Função I & Administração Geral & - \\
Programa I & - Administração central & Gab. do Secretário e Diretor-Geral \\
Programa II & - Adm. da secretaria & Direção administrativa \\
Atividade I & - Adm. contábil & Secção de contabilidade \\
Atividade II & - Adm. de pessoal & Secção de pessoal \\
Atividade III & - Adm. de material & Secção de material \\
\hline Atividade IV & - Tombo e cadastro & Secção de cadastro \\
\hline Atividade V & - Ad. orçamentária & Secção de orçamento \\
\hline Função II & Serviços industriais & - \\
\hline Programa I & - Funcionamento hidráulico & Diretoria industrial \\
\hline Subprograma I & - Adm. geral de hidráulicas & Diretoria industrial \\
\hline Atividade I & - Adm. hidráulica de São Sepé & Residência \\
\hline Atividade II & - Adm. hidráulica de Santa Rosa & Residência \\
\hline Subprograma II & - Exame bacteriológico de água & Laboratório central \\
\hline Subprograma III & - Aquisição, guarda e distribuição de material & Secção de almoxarifado \\
\hline
\end{tabular}

Fonte: Machado Jr. (1967)

Ao se analisar com maior profundidade tal classificação, verifica-se que, na verdade, sua base primária é a unidade de administração. De fato, em um orçamento-programa real, as obras públicas não se apresentam reunidas em uma 'Secretaria", mas se especificam por função. Houve, no Rio Grande, uma confusão de conceitos. Por exemplo, "Construção de Postos de Saúde" aparece como um subprograma da função I — Obras Públicas. Na realidade, "Construção de Postos de Saúde" é um subprograma da função "SAÚDE". A construção é mera atividade-meio e não uma função ou um programa em si mesmo. 
Orçamento de Capital

\begin{tabular}{|lll|}
\hline Função & Programa & Órgão executor \\
\hline Função I & Obras públicas & - \\
Programa I & - Construção e ampliação de prédios públicos & Diretoria de obras \\
Subprograma I & - Elaboração de projetos & Sec. de estudos e projeto \\
Subprograma II & - Construção de prédios para exatorias & Sec. de obras novas \\
Projeto I & - Construção da exatoria de Sapucaia & Sec. de obras novas \\
Projeto II & - Construção da exatoria de Viamão & Sec. de obras novas \\
Subprograma III & - Construção de postos de saúde & Sec. de obras novas \\
Projeto I & - Construção do posto de saúde de Quaraí & Sec. de obras novas \\
Programa II & - Reforma e restauração de prédios públicos & Diretoria de obras \\
Projeto I & - Reforma do edifício da secretaria de saúde & Secretaria de conservação e cadastro \\
Projeto II & - Restauração do monumento a Júlio de Castilhosos & Secretaria de conservação e cadastro \\
Função II & Saneamento & \\
Programa I & - Água e esgoto & Diretoria de saneamento \\
Subprograma I & - Elaboração de projetos & Sec. de estudos e projetos \\
Subprograma II & - Construção de hidráulicas & Sec. de execução e fiscalização \\
Projeto I & - Construção da hidráulica de Sarandi & Sec. de execução e fiscalização \\
\hline
\end{tabular}

Fonte: Machado Jr. (1967)

Tal conclusão é não só lógica, como de uma clareza meridiana. Nesse sentido, aliás, é a lição de Jesse Burkhead:

Second, the functional classification does not identify public works as a separate category. A specific public works outlay, such as a bridge, would fall under transportation; ... Public works are therefore viewed not as significant in themselves, but as important only in their relation to the interest served by governmental programs. ${ }^{4}$

Ademais não se penetrou com mais profundidade na análise administrativa a fim de, ao nível de seção, identificarem-se os grupos homogêneos. A ideia da classificação na unidade de organização dominou toda a tessitura do orçamento-programa do governo estadual do Rio Grande.

De qualquer modo, a experiência foi válida. Lamentável foi, tão somente, que ela tivesse sido descontinuada, justamente na época em que o governo federal fazia a primeira tentativa séria de programar suas despesas.

Nosso desejo era no sentido de que os técnicos gaúchos tivessem sido mais persistentes e, com todos os seus erros, continuassem a experiência, melhorando-a ano a ano, e ficamos ainda à espreita de que novas tentativas sejam levadas a cabo na terra dos pampas.

\footnotetext{
${ }^{4}$ Burkead, Jesse. Government budgeting. Nova York: John Wiley \& Sons, Inc., 1956. p. 117.
} 


\section{Guanabara}

Não é nosso objetivo o estudo do aspecto político bastante saliente quando o governador enviou sua primeira proposta nos moldes de orçamento-programa. Esse aspecto foi exaustivamente estudado pelo prof. Frank Sherwood em monografia intitulada A adoção do orçamentoprograma pelo estado da Guanabara. ${ }^{5}$

O orçamento-programa da Guanabara apresenta um aspecto técnico de maior precisão, porque foi precedido de uma pesquisa geral dos aspectos de engenharia, economia, geografia, estatística e finanças públicas do estado, publicados em volume sob o título Estudos cariocas. ${ }^{6}$

As Normas de elaboração da proposta orçamentária para 1965, publicadas pelo Serviço de Divulgação da Secretaria do Governo, introduziram uma nomenclatura diferente da que vinha sendo utilizada no Brasil, com a distribuição das funções do governo em Campos que, nas propostas anteriores, eram denominados de Projetos.

Os Campos definem as Normas acima citadas, "representam os grandes setores em que se desenvolve a atuação do Governo, aplicando às condições da Guanabara parte das funções definidas na Lei Federal no 4.320/64, que padronizou os orçamentos públicos no Brasil".

Os Campos são compostos pelos programas que representam "a ordenação racional das atividades em setores específicos em obediência às diretrizes firmadas pela Alta Administração. Os Programas se compõem, por sua vez, de Projetos (ou Operações) que representam as obras, serviços e empreendimentos que definem os objetivos específicos pretendidos". (Normas, p. 2/2).

Os projetos (operações), programas e campos são definidos ao nível da Unidade Orçamentária (Art. 14 da Lei oo 4.320/64). As próprias Normas exemplificam: "as atividades do Departamento de Educação Primária devem ser classificadas no Programa de Ensino Primário, não obstante poder apresentar atividades subsidiárias de apoio, como Administração de Pessoal, que não devem merecer destaque especial". (Normas, p. 2/2).

"Contudo", (continuam as Normas) "já o Departamento de Ensino Médio e Superior, pela natureza de suas atividades, apresentará Programas de Ensino Técnico e Secundário, Formação e Aperfeiçoamento do Magistério, Atividades Complementares do Ensino. Da mesma forma, não classificaremos como Programas as atividades subsidiárias de apoio (Administração de Pessoal, Contabilidade etc.). Nesse caso, porém, as atividades de natureza administrativa comuns a esses programas deverão se classificar como Administração de Projetos Específicos da Secretaria."

Os Programas são em seguida desdobrados pelas categorias econômicas.

Criada a nomenclatura para a classificação por categoria funcional e estabelecidas as Unidades Orçamentárias, as Normas, como vemos, deixaram o estabelecimento dos Programas ao nível de execução.

\footnotetext{
${ }^{5}$ Sherwocd, Frank P. A Adoção do orçamento-programa pelo estado da Guanabara. Rio de Janeiro: Fundação Getulio Vargas, 1966. (Série Cadernos de Administração Pública, n. 62).

${ }^{6}$ Estado da Guanabara, Secretaria do Governo, Coordenação de Planos e Orçamento, 1965.
} 
Se isto, por um lado, requer uma pesquisa intensa de análise administrativa, por outro, torna o orçamento mais exato, mais empírico, mais próximo da realidade, além de atribuir a responsabilidade ao nível de execução, permitindo que cada setor interessado em uma atividade participe também da elaboração da proposta orçamentária.

Não temos meio para dizer se esta descentralização no processo decisório foi levada a efeito no estado da Guanabara; estamos, apenas, asseverando que as instruções emitidas, se convenientemente aplicadas, conduzem a tal resultado.

Tomemos, ainda às Normas, alguns exemplos de Unidade Orçamentária, Campo e Programa, ou seja, a distribuição dos Campos pelas Unidades Orçamentárias:

\begin{tabular}{|c|c|c|c|}
\hline Órgão Superior & Unidades Orçamentárias & Campos & Programas \\
\hline Casa Civil & Assessoria do Trabalho & Bem-Estar Social & Assistência Social \\
\hline Secretaria de Administração & $\begin{array}{l}\text { Conselho de Treinamento do } \\
\text { Estado }\end{array}$ & Administração Geral & $\begin{array}{l}\text { Administração de } \\
\text { Pessoal }\end{array}$ \\
\hline Secretaria de Economia & Departamento de Veterinária & $\begin{array}{l}\text { Desenvolvimento } \\
\text { Econômico }\end{array}$ & $\begin{array}{l}\text { Fomento à Produção } \\
\text { Agropecuária }\end{array}$ \\
\hline \multirow[t]{2}{*}{ Secretaria de Educação } & $\begin{array}{l}\text { Departamento de Educação } \\
\text { Primária }\end{array}$ & Educação e Cultura & Educação Primária \\
\hline & $\begin{array}{l}\text { Departamento de Educação } \\
\text { Média e Superior }\end{array}$ & Educação e Cultura & $\begin{array}{l}\text { Atividades Complementares } \\
\text { do Ensino }\end{array}$ \\
\hline Secretaria de Finanças & Conselho de Contribuintes & Administração Geral & Administração Fazendária \\
\hline Secretaria de Governo & $\begin{array}{l}\text { Coordenação de Planos e } \\
\text { Orçamentos }\end{array}$ & Administração Geral & Planejamento \\
\hline \multirow[t]{3}{*}{ Secretaria de Obras Públicas } & $\begin{array}{l}\text { Departamento de Eng. } \\
\text { Urbanística }\end{array}$ & Administração Geral & Planejamento \\
\hline & Sursan & Saneamento do Meio & $\begin{array}{l}\text { Drenagem e Saneamento } \\
\text { básico }\end{array}$ \\
\hline & $\begin{array}{l}\text { Departamento de Estradas e } \\
\text { Rodagem }\end{array}$ & $\begin{array}{l}\text { Urbanização, Viação e } \\
\text { Comunicações }\end{array}$ & Viário \\
\hline Secretaria de Saúde & $\begin{array}{l}\text { Divisão de Fiscalização da Me- } \\
\text { dicina }\end{array}$ & Saúde & $\begin{array}{l}\text { Pesquisa, Fiscalização e } \\
\text { Educação Sanitária. }\end{array}$ \\
\hline
\end{tabular}

Fonte: Machado Jr. (1967)

Verifica-se que, apesar da melhoria técnica em comparação com o sistema do Rio Grande do Sul, há ainda muita aderência à unidade orçamentária. Evidentemente não nos move a intenção de abolir a unidade orçamentária responsável pela execução de um projeto ou atividade onde se formaliza a responsabilidade individual do administrador pela movimentação dos fundos públicos para a consecução de uma meta bem definida. Apenas observamos que, em uma classificação por categorias funcionais, a ênfase deve ser atribuída aos programas, projetos e atividades. 
A análise da própria proposta orçamentária demonstra o interesse pela mensuração do trabalho, unicamente, porém, nas obras de engenharia. Assim, no Programa "Esgotos" ficamos informados que a dotação atribuída destinava-se à execução, sob a orientação normativa, o controle técnico e a fiscalização específica do órgão central, de $30.000 \mathrm{~m}$ de canalização de esgotos sanitários, em diversos logradouros da zona rural e suburbana, entre outros os das ruas Fábio da Luz, Camará, Camboriú e Bráulio Cordeiro, inclusive obras de reposição de pavimentação.

Não nos informa, todavia, a proposta, a distribuição de outros recursos, como tempo de execução, pessoal necessário, material etc. Há indicação, apenas, das dotações em dinheiro.

Não podemos informar também até que ponto as unidades de medidas são, na prática, utilizadas para controle da execução orçamentária, no forma do parágrafo único do artigo 79 da Lei no 4.320/64.

Na proposta para 1966 há uma pequena variante da classificação adotada anteriormente. A despesa apresenta-se dividida pelos três poderes: Judiciário, Legislativo e Executivo. Neste último, discriminada pelas Secretarias de Estado e pelas Unidades Orçamentárias, nível em que as despesas se subdividem em despesas de atividades-meio e de atividades-fim. As primeiras constituem o anexo II, denominado "despesas com a Administração Pública”, e as segundas, o anexo IV, crismado com o nome de "despesas com o Desenvolvimento Econômico e Social".

Os Projetos foram reduzidos a nove, numa adaptação da Lei no 4.320/64 às condições peculiárias do estado da Guanabara:

1 - Administração Superior

2 - Administração Geral

3 - Administração dos Projetos Específicos

4 - Educação e Cultura

5 - Saúde

6 - Bem-Estar Social

7 - Desenvolvimento Econômico

8 - Saneamento do Meio

9 - Urbanização, Viação e Comunicações

Os projetos são subdivididos em 68 programas. $^{7}$

Como se verifica, trata-se de um trabalho tecnicamente sério, embora tenha desprezado a nomenclatura correntemente aceita para adotar uma própria para o estado.

\footnotetext{
${ }^{7}$ Governo Carlos Lacerda. Mensagem à Assembleia Legislativa - Mensagem 28, em 31 de agosto de 1965. Rio de Janeira: Imprensa Oficial do Estado. p. 177.
} 


\section{Brasília}

A Prefeitura do Distrito Federal, pelo Decreto no 404, de 27 de abril de 1965, estabeleceu "Normas para Elaboração da Proposta Orçamentária do Distrito Federal", instituindo, "em caráter obrigatório, para todo o complexo administrativo local, as normas do OrçamentoPrograma". ${ }^{8}$

Em Brasília está assente que o orçamento-programa não se limita à fase de elaboração, mas dá o passo à frente para que o controle da execução orçamentária seja realizado em termos financeiros, para a Divisão de Orçamento, e em aspectos físicos, correspondendo à concretização de metas, para a Divisão de Supervisão do Plano.

Informa-nos a exposição do secretário de governo ao prefeito, na apresentação da proposta para 1967, que "o Controle por relatórios já foi implantado e a continuidade administrativa o está sedimentando. No próximo exercício podemos prever, com segurança, a instalação da Sala de Operações, especialmente porque os órgãos menos adaptados à nova sistemática de acompanhamento e controle, como a Novacap, o DER e o Gabinete do Prefeito, já estarão devidamente condicionados às rotinas aprovadas". 9

Saudamos, sem dúvida nenhuma, esta evolução, porque muito se tem escrito, no Brasil e no exterior, sobre elaboração orçamentária, na presunção de que, assim, talvez, se esteja, concomitantemente, penetrando na fase de controle. Tal presunção, infelizmente, não é verdadeira. A fase de controle há de ser tratada em separado porque exige técnicas, métodos e sistemas próprios. Já se disse que uma das razões das falhas de nossos planos governamentais tem residido na inexistência de um sistema de controle eficaz, permanecendo a ênfase exageradamente no controle jurídico-político, ou seja, em seu aspecto puramente formal. À medida que uma unidade da Federação cria um sistema de relatórios para o acompanhamento e controle interno do orçamento em seus aspectos monetário e físico, nós outros que temos, por tal medida, nos batido na cátedra da Ebap, temos o dever de, calorosamente, enviar à equipe da Secretaria de Governo de Brasília nosso apoio e votos para que tal trabalho prossiga vitoriosamente.

A Secretaria de Governo promete continuar as pesquisas e análises para o encontro de unidades de medida capazes de permitir o mensuramento das transações governamentais, facilitando, assim, a elaboração e a execução do orçamento, in verbis:

O acompanhamento físico, entendido como a ideia correta do que se está realizando, por outro lado, ainda não se consubstanciou porque a unidade de trabalho, ponto de referência, isto é, metas e programas, não está inteiramente institucionalizada. Essa dificuldade só será superada quando for :

1ㅇ) - aprovado o Plano-Diretor do Distrito Federal, em cumprimento da Lei ํㅜ 4.766, de 30 de agosto de 1965;

\footnotetext{
${ }^{8}$ Distrito Federal - Orçamento-Programa - 1967: Mensagem do secretário de governo ao prefeito da capital. p. 1.

${ }^{9}$ Idem, p. 2.
} 
$2^{\circ}$ ) - adaptada a Contabilidade do Distrito Federal à reforma exigida pelo orçamento-programa; e

3o) — tornada efetiva a ação da Divisão de Supervisão do Plano em termos de controle Pert, e outros de execução. ${ }^{10}$

É auspicioso notar o enfoque que o secretário de governo da capital federal dá ao problema da contabilidade. De fato, como já assinalamos no início deste artigo, sem que a contabilidade se adapte às normas do orçamento-programa não é, na realidade, possível empreender a longo prazo a implantação dessa técnica, porque, pouco a pouco, vão minguando elementos de comparação, de exercício a exercício, capazes de mostrar, no tempo, os resultados da ação do governo. Impõe-se, portanto, que a contabilidade renove seus métodos e passe a controlar a execução do orçamento por contas estruturadas em programas de trabalho, isto é, da mesma forma por que o orçamento é preparado.

É de reconhecer-se, por outro lado, que a Lei no 4.320/64 deve, outro tanto, ser reformada para dar mais ênfase à contabilização por programas, ao invés de fazê-lo por categorias econômicas.

A classificação da despesa, por programas, na prefeitura de Brasília, segue a metodologia adotada pelo Ministério do Planejamento e Coordenação Econômica, adaptada às circunstâncias da capital do país.

Apresenta-se dividida em 21 programas, subdivididos, por sua vez, em tantos subprogramas quantos necessários para melhor especificação da despesa que é, também, demonstrada pelas unidades administrativas e pelas categorias econômicas.

Para cada programa, foram identificados, pelo menos, dois subprogramas comuns "Administração" e "Treinamento e Aperfeiçoamento de Pessoal".

O enfoque classificatório por unidades administrativas, ou unidades orçamentárias, é, já aqui, bem menor, o necessário para atender às exigências legais. Toda a especialização da despesa é feita por programas e subprogramas, nos quais se coloca a atividade que se constitui em grupamento de despesas para manutenção dos órgãos existentes, como veremos mais adiante. Parece, entretanto, pela leitura da proposta para 1967, que não foi feita a distinção entre atividade e projeto, como faz o Ministério do Planejamento.

Por sua vez, a classificação por categorias econômicas aparece como elemento subsidiário no fim da especificação por programas em cada Secretaria. Isto dá o verdadeiro enfoque à classificação por categorias funcionais, como convém na atual revolução orçamentária por que passa o Brasil.

A tentativa de mensuração é encontrada em alguns subprogramas, especialmente nos que dizem respeito aos investimentos. Assim, na Secretaria de Viação e Obras encontramos referência a unidades físicas, como "construção de tantos blocos de apartamentos", "construção de tantas casas para funcionários" etc.

${ }^{10}$ Idem, p. 2. 
Note-se que também Brasília não está incluindo as obras públicas como um projeto específico de um programa ou subprograma, mas deixando-as segregadas, como se tal fosse uma atividade-fim. Já nos referimos a esse ponto ao estudar o orçamento do Rio Grande do Sul.

De qualquer modo, contudo, o trabalho da equipe da Prefeitura do Distrito Federal, se continuadas as pesquisas para aperfeiçoamento da técnica orçamentária, é dos mais promissores.

\section{Governo Federal}

Forçado pela necessidade premente de racionalizar as finanças da União, frente a um déficit orçamentário e de caixa de natureza permanente e crescente, o governo federal não teve outra alternativa senão a de adotar a técnica do orçamento-programa, como um instrumento de planejamento global da ação do governo, como um meio de comando da conjuntura econômica do país, como um processo de comando da administração pública, e, por fim, como um sistema de programação dos desembolsos do Tesouro Nacional.

Das propostas até agora produzidas pelo Ministério do Planejamento e Coordenação Econômica pode-se inferir que seus técnicos estão seguindo as pegadas da Cepal com algumas modificações. Parece-nos que os conceitos seguintes estão adequados para exprimir a nomenclatura utilizada. Devemos esclarecer, entretanto, que os conceitos dados abaixo não são da responsabilidade do MPCE, nem, individualmente, de qualquer de seus técnicos. Procuramos inferi-los partindo da análise das propostas orçamentárias já publicadas e da teoria desenvolvida no material cedido pela Cepal. Teríamos, então, frente ao caso brasileiro:

Função: um dos campos bem delineados em que se faz sentir a ação do governo: educação, segurança pública, defesa nacional, serviços urbanos, saúde, higiene etc. etc.

Programa: uma dessas funções, quando convenientemente correlacionada com os recursos financeiro, humano, temporal, espacial etc. Tais recursos tornam a ação do governo capaz de ser levada à prática. Quando alguém se refere, em termos de programa, à saúde pública, já pressupõe a existência de uma pesquisa prévia, de um levantamento das necessidades e um estudo dos recursos disponíveis, bem como o estabelecimento de um curso de ação tendo em vista todos esses elementos e a meta a alcançar. Podemos mesmo imaginar a existência da função sem a correspondente existência do governo e este surgiria, na sociedade humana, como uma agência para a exercitação das operações necessárias ao cumprimento das funções. Faria isto através dos programas de trabalho, ou, simplesmente, dos programas.

Poder-se-á argumentar que estamos confundindo os conceitos de "função" e de "necessida-

de". É possível, mas sob o aspecto puramente pragmático, a confusão seria perfeitamente lógica e desejável. Aos economistas e sociólogos compete a crítica; aos orçamentistas, idealizar uma nomenclatura que lhes permita o entendimento e a realização eficaz e eficiente de trabalhos.

Subprograma: é um segmento ou uma parte bem definida de um programa. O subprograma é estabelecido por razões de ordem prática, a fim de facilitar programação e controle da execução de um programa, inclusive a delegação de autoridade. O grupo abaixo, retirado do orçamento de Brasília, dá uma ideia do que sejam um programa e um subprograma: 
— Açudagem

Programa

— Administração Subprograma

- Construção de Barragens Subprograma

- Construção de Sistema de Irrigação e Drenagem Subprograma

- Conservação e Recuperação Subprograma

— Treinamento e Aperfeiçoamento de Pessoal Subprograma

— Estudos e Pesquisas Subprograma

Atividade: uma operação necessária para manter o subprograma em funcionamento normal, isto é, corresponde às operações de manutenção. Compõe-se, na maioria, de despesas correntes, mas pode, também, comportar algumas despesas de capital imprescindíveis à manutenção do subprograma, como, por exemplo, material permanente, instalações ou outros investimentos que não determinem ampliação do subprograma. A substituição do mobiliário escolar pode servir de exemplo de uma despesa de capital apropriada a uma atividade.

Subatividade: às vezes, por razões de natureza prática, faz-se necessário subdividir uma atividade, como se subdividiu o programa, aparecendo, dessa forma, as subatividades.

Projeto: corresponde às operações necessárias à criação de novas atividades, ou à ampliação das já existentes, ou, ainda, à formação de bens de capital de natureza econômica ou social. O asfaltamento de uma estrada de rodagem é tipicamente um projeto dentro do subprograma "Rodoviário" do programa "Transportes".

Desse modo, as categorias da classificação por programa seriam:

PROGRAMA — SUBPROGRAMA $\left\{\begin{array}{l}\text { Atividade — Subatividade - } \\ \text { Tarefa } \\ \text { Projeto — Obra }\end{array}\right.$

A tarefa e a obra, entre outras, seriam as subdivisões necessárias, respectivamente, da subatividade e do projeto. Em termos de exemplificação:

TRANSPORTES - RODOVIÁRIO $\left\{\begin{array}{l}\text { Conservação de estradas } \\ \text { Asfaltamento de estradas }\end{array}\right.$

Completando as definições:

Plano: a integração de todos os programas administrativos, com seus elementos de execução, de forma operacional.

Planejamento: corresponde às fases sucessivas de um processo contínuo e sistemático para a estruturação de um plano. 
A programação se concretiza e torna-se mais objetiva quando o plano de ação apresenta-se expresso em termos financeiros e de unidades físicas, capaz, assim, de dar a todos os interessados uma visão, inclusive, de custo unitário.

Plano de ação: estabelecido em termos dos objetivos ou metas a alcançar e dos recursos humanos, materiais, financeiros, e de tempo, necessários à sua execução, classificados por programas, subprogramas, atividades, subatividades, tarefas, projetos e subprojetos (quando necessário) e obras.

Essa é a nomenclatura básica para a classificação das transações governamentais por categorias de programas expressas em contas. O nível em que o programa, o subprograma, a atividade, a subatividade e o projeto devem ser estabelecidos é uma questão de natureza prática que somente a pesquisa e o interesse do administrador podem determinar. Entretanto, é conveniente, sem adoção de uma padronização rígida, estabelecerem-se níveis uniformes através de toda a administração pública brasileira, em qualquer esfera de governo na Federação.

Não somos apologistas da padronização excessiva, embora reconheçamos que ela produziu seus frutos no sistema estabelecido pelo Decreto-Lei no $2.416 / 40$, numa época em que não havia nem sombra de uniformização na classificação das contas públicas pelo Brasil afora e quando o governo, em qualquer de suas órbitas, realizava serviços de natureza restrita.

Hoje, que o governo cresceu como uma agência do desenvolvimento econômico e social, suas operações são múltiplas e caminhamos para a introdução do orçamento-programa, não vemos como possamos adotar uma classificação rígida.

Se o orçamento-programa expressa um programa do governo, parece-nos impossível que União, estados e municípios tenham o mesmo plano de contas, a menos que padronizemos os programas...

O Ministério do Planejamento já deu a ordem de partida para um plano de contas, mais amplo, por categorias de programas, reformulando a classificação adotada pela Lei n⿳o 4.320/64.

A Proposta Orçamentária para o Exercício de 1967, Projeto no 3.800, de 1966, da Comissão de Orçamento, apresenta, de acordo com a própria Mensagem Presidencial, a classificação de todas as categorias econômicas em Programas, e Subprogramas, subdivididos estes em Projetos e Atividades. Logo a seguir, a Mensagem Orçamentária explica a técnica utilizada para o orçamento-programa do governo federal:

Os orçamentos parciais dos diversos departamentos e serviços incluídos na Proposta serão constituídos por duas partes: os "recursos atribuídos" aos órgãos, classificados pela natureza da despesa e o "Programa de Trabalho", classificando os diversos projetos, no referente às despesas de capital, e as atividades, no referente às despesas correntes. ${ }^{11}$

${ }^{11}$ Diário do Congresso Nacional, Seção I, Suplemento ao nº 105, p. XXI. 
De fato, a Proposto mostra, em cada Ministério, por sua departamentalização, a despesa classificada pelas categorias econômicas e um segundo quadro resumindo-a por programa e subprograma, com o desdobramento em projeto e atividade. Pode-se verificar que um dado "programa" contém, na mesma unidade orçamentária, todas as despesas de capital e correntes, não incidindo, assim, o governo federal no erro de levar para o Ministério da Viação e Obras Públicas as despesas com obras, as quais se apropriam ao Ministério diretamente interessado. Aliás, isto já vinha sendo feito no governo federal, de algum tempo a esta parte, com a modificação das estruturas organizativas, tornando-se cada vez mais o Ministério da Viação e Obras Públicas um órgão de Energia, Transportes, Comunicações, Saneamento e Açudagem. Mudou de função, conservando um nome arcaico.

Como exemplo do sistema de classificação por programas adotado no orçamento da União, transcrevemos, a seguir, um quadro demonstrativo tomado ao acaso.

\begin{tabular}{|c|c|c|c|c|}
\hline & 4.06.12 - DIRETORIA DO ENSINO & OMERCIAL & & $\begin{array}{c}\text { Execução } \\
\text { Direta } \\
\text { Cr\$ } 1.000\end{array}$ \\
\hline \multirow{2}{*}{$\begin{array}{c}\text { Programa } \\
\text { Subprograma } \\
\text { Projeto (1) } \\
\text { Atividade (2) } \\
\text { N. }{ }^{\circ} \text { de ordem }\end{array}$} & \multirow{2}{*}{ ESPECIFICAÇÃO } & \multicolumn{2}{|c|}{ DESPESA } & \multirow{2}{*}{ Total } \\
\hline & & Projeto & Atividade & \\
\hline & EDUCAÇÃO & & \\
\hline & Ensino Médio & & & 4.729 .882 \\
\hline \multirow{2}{*}{$\begin{array}{l}04.03 .1 .0871 \\
04.03 .1 .0872\end{array}$} & Reequipamento da Unidade & \multicolumn{2}{|l|}{16.000} & \\
\hline & $\begin{array}{c}\text { Ampliação do prédio do Colégio Comerciol Prof. Clóvis } \\
\text { Salgado } \ldots \ldots \ldots \ldots \ldots \ldots \ldots \ldots \ldots \ldots \ldots \ldots \ldots \ldots \ldots \ldots \ldots \ldots\end{array}$ & \multicolumn{2}{|l|}{200.000} & \\
\hline \multirow[t]{2}{*}{04.03 .2 .0874} & $\begin{array}{l}\text { Administração da Diretoria do Ensino Comercial ....... } \\
\text { Monutenção do Companha de Aperfeiçoomento e Expan- }\end{array}$ & & 2.863 .882 & \\
\hline & são do Ensino Comercial . . . . . . . . . . . . & & \multirow{2}{*}{$\begin{array}{r}600.000 \\
50.000\end{array}$} & \\
\hline \multirow[t]{2}{*}{$\begin{array}{l}04.03 \cdot 2.0875 \\
04.03 .2 .0876\end{array}$} & $\begin{array}{l}\text { Manutenção de atividades escolares em salas especiais } \\
\text { Centros de estágios e treinamento profissional, pela D.E.C. }\end{array}$ & & & \\
\hline & ou mediante convênios ...... & & \multirow{7}{*}{$\begin{array}{l}600.000 \\
200.000 \\
100.000 \\
100.000\end{array}$} & \\
\hline \multirow{3}{*}{$\begin{array}{l}04.03 \cdot 2.0877 \\
04.03 \cdot 2.0878 \\
04.03 .2 .0879\end{array}$} & Funcionamento do Colégio Comercial Prof. Clóvis Salgado & & & \\
\hline & Funcionamento do Escola Técnica de Hotelaria - CB . & & & \\
\hline & $\begin{array}{l}\text { Funcionamento da Escola Técnica de Hotelaria }-\mathrm{SP} \\
\text { Planos Especiais }\end{array}$ & & & 1.000 .000 \\
\hline 04.09 .1 .0880 & Instalaçắo e complementoção de equipamento de salas & & & \\
\hline & 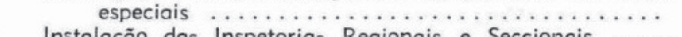 & 200.000 & & \\
\hline \multirow[t]{2}{*}{$\begin{array}{l}04.09 \cdot 1.0881 \\
04.09 .1 .0882\end{array}$} & $\begin{array}{l}\text { Instalação das Inspetorias Regionais e Seccionais ...... } \\
\text { Aperfeiçoamento de Mão-de-Obra em Atividades Terciárias }\end{array}$ & $\begin{array}{l}100.000 \\
700.000\end{array}$ & & \\
\hline & TOTAL $\ldots .$. & 1.216 .000 & 4.513 .882 & 5.729 .882 \\
\hline
\end{tabular}

Fonte: Machado Jr. (1967)

Também a União não penetrou, ainda, na era da mensuração do trabalho e não podemos informar se a contabilidade está sendo adaptada para acompanhar a execução em termos de programa, sem o que, como já vimos, a quase totalidade do esforço teria sido em vão.

Esperamos que o leitor que teve a paciência de acompanhar a presente exposição tenha obtido um panorama amplo do que se vem tentando em orçamento-programa no Brasil, com base nas experiências que vimos de descrever. 
Não temos a pretensão de ter conhecimento de todas as tentativas de introdução dessa técnica no serviço público direto. É possível que alguma autarquia, algum município, um ou outro estado, sobretudo na área da Sudene, estejam trabalhando nesse campo promissor.

Como o leitor facilmente verifica, e deixamos bem claro, esta ligeira pesquisa abrange, unicamente, o serviço público direto, pois não tivemos tempo de pesquisar as sociedades de economia mista e as empresas públicas, onde, por certo, algo já está sendo realizado para o aperfeiçoamento dos métodos de elaboração e controle do orçamento.

Por sinal, queremos dizer que o orçamento-programa não é uma panaceia, um remédio, em si mesmo, para os males do subdesenvolvimento, embora se esteja tornando um dos instrumentos mais importantes da moderna administração pública.

Não age ele por si só, também. Há de ser administrado, como tudo mais. Há de ser preparado o pessoal especializado para lidar com suas técnicas, e em torno dele é preciso formarse uma teoria precisa, sua prática deverá ser seguida com honestidade e convenientemente correlacionada com os demais instrumentos de que dispõe o administrador.

O orçamento-programa não pode constituir-se em um fracasso, pois isto iria desmoralizar uma técnica realmente valiosa no contexto da administração científica: pesquisa, investigação, experimentação, planejamento, criação de padrões de desempenho, estrutura organizativa racional, relações humanas sadias, chefias competentes, dignidade e honestidade na condução dos negócios públicos, são outros tantos ingredientes básicos do sucesso na administração pública como empresarial.

Os recursos financeiros e de outras espécies são sempre escassos e o orçamento-programa tende a maximizar os benefícios em favor da comunidade, mas, evidentemente, não dispensa o emprego dos cânones éticos fundamentais dentre os quais alguns foram acima citados, e das demais técnicas que formam a ciência da administração.

\section{Referência}

MACHADO JR., José T. A experiência brasileira em orçamento-programa - uma primeira visão. Revista de Administração Pública, Rio de Janeiro, v. 1, n. 1, p. 145-172, 1967.

José Teixeira Machado Jr. (in memoriam) foi professor da Escola Brasileira de Administração Pública da Fundação Getulio Vargas (FGV/Ebap) de 1957 a 1968. Prestou serviço como autônomo entre fevereiro e julho de 1971, participando da elaboração de um Manual de administração financeira destinado a uso no Departamento Nacional de Estrada e Rodagem (DNER). Retornou à FGV como funcionário na função de assessor na Ebap entre setembro de 1972 e julho de 1973, desligando-se então em definitivo. Teixeira Machado ingressou como técnico de administração do Instituto Brasileiro de Administração Municipal (Ibam) em 1960, realizando trabalhos de assistência técnica junto a órgãos públicos brasileiros. Entre março de 1961 e abril de 1963 ocupou o cargo de diretor-adjunto. Nessa condição, participou, entre 
outros eventos importantes, da Reunião sobre Desenvolvimento da Comunidade (Quito, Equador, patrocinada pela ONU). Após voltar à função técnica, integrou a representação do Ibam na reunião sobre financiamento municipal (BID, Washington, 1965). Nesse mesmo ano afastou-se do quadro e passou a atuar como consultor para assuntos relacionados com a administração pública. Teve ainda longa carreira como agente público no antigo Instituto de Aposentadoria e Pensões dos Industriários (Iapi) e no Banco Nacional de Desenvolvimento Econômico e Social (BNDES), além de ter atuado como professor em colégios e faculdades, sempre voltado para o ensino de normas orçamentárias, especialmente relacionadas com o denominado orçamento-programa, do qual foi um dos introdutores de seu uso no Brasil. Sua principal obra é o livro A Lei 4.320 comentada, que escreveu junto com o professor Heraldo da Costa Reis, e que no momento encontra-se na $34^{\mathrm{a}}$ edição. 